\title{
OVERCOMING OBSTACLES TO IMPLEMENTING AN OUTCOME-BASED EDUCATION MODEL: TrADITIONAL VERSUS TRANSFORMATIONAL OBE
}

\author{
Liliya Akhmadeeva \\ MEd student, Faculty of Education \\ Simon Fraser University \\ A team member of the project: \\ Implementing Outcomes Based Learning in a Canadian Engineering Program \\ lakhmade@sfu.ca \\ lahmadeeva@yahoo.com \\ Maureen Hindy \\ Lecturer, School of Engineering Science \\ Simon Fraser University \\ Co-Investigator of the project: \\ Implementing Outcomes Based Learning in a Canadian Engineering Program \\ mhindy@sfu.ca \\ Carolyn J. Sparrey, PhD, PEng \\ Assistant Professor, School of Engineering Science \\ Simon Fraser University \\ Principal Investigator of the project: \\ Implementing Outcomes Based Learning in a Canadian Engineering Program \\ csparrey@sfu.ca
}

\begin{abstract}
Attempts to introduce a new outcomebased curriculum in the Mechatronic Systems Engineering (MSE) Program at Simon Fraser University $(S F U)$ have posed a range of challenges to teaching staff and students in terms of the most effective and efficient means for transitioning the program and achieving the expected improvements in educational outcomes. However, the mechanical process of pursuing outcomes without the deliberate revision of the pedagogy, attitudes and forms of assessments fails to attain the continuous improvement concept that OBE implies. This paper analyses MSE faculty interview responses to approaches they incorporate in their teaching practices and the effect these practices have on student learning. Class size, expectations of learner characteristics and reality, teaching practice and evaluation, and student motivation were the most commonly discussed challenges. Self-
\end{abstract}

reported instructor characteristics and the perceived role of the instructor often contradicted the OBE model of learning. The results inform a critical discussion of the pedagogical aspects involved in reshaping existing curriculum to satisfy the needs of the 21st century learner. The process of transitioning from the content-driven to the outcome-based curriculum is revealing opportunities in terms of transformative teacher education as well as challenges that warrant further analysis.

Keywords: outcome-based education, transformational outcome-based curriculum, transformative teacher education, autonomous learner, engineering, instructor 


\section{INTRODUCTION}

The Canadian Engineering Accreditation Board $(\mathrm{CEAB})$ has mandated that all Canadian engineering programs completely transition to OBE methods and thoroughly document that transition by June 2015 . This paper was inspired by the initial developmental processes of transitioning from content-driven to the outcome-based curriculum in the MSE program at SFU, and faculty responses to this process.

Outcome-based education centers on the definition of learning outcomes that students must demonstrate at the point of graduation. OBE theory combines many early studies of pedagogical methods $[2,3,4,6,14]$. In practice, the OBE concept does not follow a single idea or a set of procedures but is a democratic process [8]. The most basic OBE model considers any curriculum as a structured entity with a set of learning objectives and means to achieve those objectives. The trouble is that both the learning and methods objectives are labeled outcomebased encouraging instructors to translate the existing content-based education objectives to learning outcomes reflected only in the change of the format of those content driven objectives. The starting point for most OBE efforts over the past 20 years has been the existing curriculum, not a clear picture of intended outcomes of significance for students that lie beyond the curriculum [12].

Although OBE methods are designed to improve student learning there are also concerns about the implementation of OBE. The main concern of the traditional learning outcomes model is that assessment of learning becomes an end in itself, and that immediate course objectives may differ from broader program or institutional objectives [1,13]. Effectively implementing OBE methods within the time-defined structuring of traditional curriculums and delivery mechanisms may also limit the effectiveness of the method [12]. Contrary to the traditional model, in the transformational OBE framework the course learning outcomes are linked to the program objectives and connect to objectives across other disciplines providing a continuum towards the desired end point of learning $[11,16,17]$. This can be challenging because, on the one hand, such approach to OBE places students in the center making them active and responsible learners, and on the other hand, it modifies the role of a teacher from being a "giver" and "presenter" of knowledge to a facilitator of the learning process [11] [12].

The overall objective of this research is to assess faculty attitudes and readiness for an accreditation board mandated transition from content-based education to an outcomes based model. This assessment will provide the framework for assisting faculty in making an effective and efficient transition to the OBE model. The objective of the study was to define current faculty teaching experience, philosophies, practices and determine areas of improvement that faculty would like to see incorporated in the OBE transition process.

\section{METHODS}

As part of a larger study on the mandatory transition to OBE learning in Mechatronic Systems Engineering, thirteen faculty members (13/14 full time faculty) were interviewed to gauge teaching experience, philosophy and practice. The interviews were conducted with limited educational pedagogical theory or terminology to ensure accessibility to all faculty. Faculty were invited to participate in the interviews via email. Permission to conduct the study was obtained from the MSE Department Chair and was approved by SFU Office of Research Ethics. The following questions, which focus on instructors' current teaching philosophies and practices, were asked:

1. What do you teach?

2. What are your objectives as a teacher?

3. How do you pursue those objectives?

4. How would you characterize your interactions with students? What is your role in those interactions?

5. What do you expect of your students?

6. What qualities, do you think, the learners of the $21^{\text {st }}$ century must possess?

7. How can you, as a teacher, facilitate those qualities?

8. Are there any areas in your teaching practice that you would like to improve?

9. What prevents you from making those improvements?

The interviews were treated anonymously and were recorded and transcribed. The results of the interviews were compiled to evaluated consistent themes across faculty. The results compilation focused on the challenges identified by faculty in facilitating student learning and achieving an outcome-based model within the current academic framework.

\section{RESULTS}

The answers depicted the scope of challenges that the academic staff in MSE department face in their teaching practices. Class size, expectations of learner characteristics and reality, teaching practice and evaluation, and student motivation were the most commonly discussed challenges. Teacher characteristics and the perceived role of the instructor were also discussed and often contradicted the OBE model of learning.

The most common challenge reported by faculty was managing large (and increasing) class sizes from 60-180 students. Engaging and interacting with students and 
insufficient resources were the greatest concerns for large classes. The instructors reported using various strategies to establish a welcoming and friendly rapport with students by taking or collecting pictures of students in the beginning of the class and studying their names; sending personal e-mails to students who were absent; encouraging students to ask questions; and creating space for each individual to express his/her thinking making sure that each answer has value. The large class size poses other problems such as lack of time to assist each student in his/her learning, and the insufficient number of teaching assistants. All instructors expressed a desire and willingness to improve their teaching practices and expand their knowledge on pedagogical alternatives to make students more engaged by "trying to find out how it can reasonably best work for a big class." Two instructors sought assistance from the Teaching and Learning Center at SFU, one attended the workshop targeted to remodeling a course, and one asked an outside person to provide feedback on what he observed in the classroom during a lecture.

A second challenge described by instructors is the gap in the desired features thought to be possessed by the $21^{\text {st }}$ century students and the features demonstrated by the current students. The instructors characterized students of the $21^{\text {st }}$ century as individuals who easily adapt to a continuously changing environment; take ownership of their own learning, can handle the enormous amount of information, being termed by one of the instructors as "tsunami of information"; are creative and can think outside of the box; seek answers to such questions as "why they need it" and "how to do it", are inquisitive; are able to "challenge the authority and established wisdom"; and have "multidisciplinary sense" of industry they are going to be in. Instructors' answers reflect a concern that current students are resistant to change and unwilling to exercise creative thinking skills necessary for the desired qualities of $21^{\text {st }}$ century learners. In answer to the question, what qualities the learners of the $21^{\text {st }}$ century must possess, one instructor provided an example:

"I asked them to solve the math equation, and these are the learners of the $21^{\text {st }}$ century, right, what they have done so far for the past three days, they try to "google", looking at hundreds of papers to see if they can find the solution to that. They could have spent the time and solve it, and they could have solved it. Instead, they spent those three days trying to find the solution. They don't want to solve the problem; they want to see solved problems."

Instructors reported that very often students prefer to passively receive information rather than actively participate in their own learning. This discrepancy in instructor and student expectations of teaching can lead to poor teaching evaluations. One instructor observed that the current evaluation system can demotivate and dispirit instructors resulting in stagnant and chronically ill educational practices. The current learning behavior was described by one of the instructors as follows:

"A lot of people say that the teacher's job is to facilitate, and facilitating is quite different from teaching. Students tend to look at teaching as just one way traffic, so there should be the understanding from students that, yes, they come to class to participate, not to be entertained, it is different than seeing a movie where you go to the theater, you lie down, enjoy and not participate, and then when you leave the movie, and you just summarize the plot in one sentence. But learning is different from summarizing; it is the process of changing behavior. "

Instructor comments also disclosed a concern that there might be a discrepancy between the focus of their teaching objectives and OBE's promotional goals. Most of the instructors named the delivery of information to students as their primary teaching objective. This objective was expressed in various forms such as, "transmitting the information", "conveying knowledge", "instilling" and "giving" the understanding, "covering fundamentals and basic material."

Finally, instructors acknowledged motivation as the main factor necessary for students to be engaged in the classroom. They report that it is a real challenge to motivate $1^{\text {st }}$ and $2^{\text {nd }}$ year students, but less challenging with respect to $3^{\text {rd }}$ and $4^{\text {th }}$ students who tend to be more focused:

"It is not really difficult for me to engage and interact with the $4^{\text {th }}$ year students; they usually have the desire to learn in that area. It is different in a $2^{\text {nd }}$ year course. They just don't have choice, they have to show up. It motivates the $1^{\text {st }}$, and $2^{\text {nd }}$ year students when the course becomes an eye opener for them, when they are exposed to real engineering."

\section{DISCUSSION AND CONCLUSIONS}

In this paper we share concerns, from the pedagogical point of view, about various approaches to learning outcomes. We reviewed OBE models and the translation of theory to practice in implementing OBE models in the classroom. Faculty responses to questions about their teaching philosophy inform a critical discussion of pedagogical aspects that are involved in the reshaping of the existing curriculum. Although significant efforts have been made to study the learning value and 
student response to $\mathrm{OBE}$ methods there is much less research on the faculty responsible for implementing OBE methods, particularly in an externally mandated transition. This study will provide the basis for developing effective and efficient methods for assisting faculty in transitioning a Canadian engineering program to OBE methods.

Through the survey MSE faculty reported a number of concerns on the practical implementation of OBE methods and improving the student experience. Large class sizes were the most often reported concern. Large class sizes are a reality in most engineering programs and are not unique to the MSE program at SFU. There is substantial research into effective methods for managing larger classes. Killen [7] suggests that overcrowded classes may be split in a practical way, and it is not the time that students spend in class that matters but what they learn. Clear teaching objectives and predefined expectations may inspire students to become smart investors in their future by being creative and innovative thinkers. Asking the right questions and setting up the right objectives may elevate the teaching process on another level of meaning helping students to become high achievers not only within the classroom walls but also out in the world. Teachers can help students become authentic learners by avoiding the concept of right and wrong answers but rather developing the notion of best practices within a particular context [15].

Killen [7] suggests that for successful learning to happen, teachers must use a variety of instructional methods, both direct and "student-centered"; provide a variety of opportunities for students to practice new knowledge; help students bring each learning episode to personal closure so as to show them where this new knowledge will lead. Teachers will have to take students' perspective and ask some basic questions including: What do I have to learn? Why do I have to learn it? What will I be doing while learning? Will it be interesting and useful? How will I know that I am learning what I should be learning? Will I have any say in what I learn? How will I be assessed?

Student motivation and engagement in the classroom were also highlighted as areas of concern from the faculty. Although the faculty identified the need for students to be active learners, when asked to define the instructor's roll in the classroom most faculty responded with traditional perspective of the linear transmission of information. This contradiction may be a key element of the current conflict in the classroom between passive and active learning. Recent thoughts on learning suggest that teachers should avoid linearly transmitting information based on habit formation and memorization, and rather actively involve students in their own learning through experience, reflection and action [10]. Unless knowledge ownership shifts from teacher to student, it cannot be claimed to have been learned [15]. In order to avoid such a situation, students need to feel that they also have power to be legitimate speakers, practitioners, and professionals in the classroom. Student resistance to active learning may also be the result of a "banking system" described by Freire [5] in which students' primary goal throughout their school-life was to be ready for a test. Within the passive learning framework, students believe that the "right answer exists somewhere for every problem, and authorities know them. Right answers are to be memorized by hard work [9, p. 79].”

Killen [7] identifies three requirements for students to stay motivated and be effective learners: "students need to know why they are learning whatever they are learning, they need to see some value in this learning, and they need to believe that they can be successful [7, p. 10]." In this case the teacher becomes a facilitator, and "cannot claim to be teaching unless learners are learning [7, p. 11]."

Transformational OBE does not prescribe a particular recipe for successful teaching; however, some thoughts expressed in this paper might be able to open up space for new ways for the curriculum in action characterized by active learning within the community of practice, where students in the classroom are treated as legitimate speakers and practitioners rather than passive receivers of knowledge [15]. Such a mental framework involves reflective analysis of current teaching and learning practices, and requires courage, faith and commitment. Transformation requires every stakeholder to be personally responsible to help create new futures, to ask questions, to take risks, and to make a difference. Engineering schools in Canada today have an opportunity to develop an effective model of transformative education that, from the very first day students step into the university, will build on their passion to relate to the world in a meaningful way.

We do not suggest that the reshaping of the existing curriculum to OBE methods is going to be easy, yet we consider the transition as work in progress ensuring qualitative outcomes and continuous improvement. The process of transitioning from the content-driven to the outcome-based curriculum is revealing opportunities as well as challenges that warrant further analysis.

\section{Acknowledgements}

This study was funded by a Teaching and Learning Grant through the Teaching and Learning Centre at Simon Fraser University. 


\section{References}

[1] David Andrich, "A framework relating outcomes based education and the taxonomy of educational objectives," Studies in Educational Evaluation, vol. 28, pp. 35-59, 2002.

[2] Benjamin S. Bloom, B.S. (Ed.), Taxonomy of Educational Objectives: The Classification of Educational Goals. Volume 1, New York: David McKay, 1956, 403 pp.

[3] Bejamin S. Bloom, Every Kid Can: Learning for Mastery. Washington, DC: College/University Press, 1973, $30 \mathrm{pp}$

[4] Lillian H. Franc, Competence-based Education: Toward Improving Patterns of Instruction. Durham, NH: New England Teacher Corps Network, 1978, 227 pp.

[5] Paulo Freire, Pedagogy of the Oppressed. New York: Continuum, 2005, 195 pp.

[6] Robert Glaser, "Instructional technology and the measurement of learning outcomes," American Psychologist, vol. 18, pp. 519-521, 1963.

[7] Roy Killen, "Outcomes-based education: principles and possibilities," Unpublished manuscript. University of Newcastle, Australia: Faculty of Education, 2000.

Available as of April 11, 2013 from

http://www.schools.nt.edu.au/curricbr/cf/outcomefocus/Ki llen_paper.pdf.

[8] Michael J. Lawson and Helen Askell-Williams, "Outcome- based education". Discussion Paper Prepared for the Association of Independent Schools of SA. Centre for the Analysis of Educational Futures: Flinders University, April 2007
[9] William G. Perry, Jr., "Cognitive and ethical growth: the making of meaning," In The modern American College, Arthur W. Chickering (ed.) (San Francisco: Jossey-Bass, 1981), 810 pp., 1981

[10] Alan Rogers, Teaching Adults. Buckingham: Open University Press, 1996 (2nd ed.), 296 pp.

[11] William G. Spady, Outcomes Based Education: Critical Issues and Answers. American Association of School Administration: Arlington, Virginia, 1994, 207 pp.

[12] William G. Spady and Kit J. Marshall, K. J., "Beyond traditional outcome-based education," Educational Leadership, vol. 49, no. 2, pp. 67-72, 1991.

[13] Bruce W. Tuckman, Testing for Teachers. San Diego: Harcourt Brace Jovanovich, 1988, 248 pp.

[14] Ralph W. Tyler, Basic Principles of Curriculum and Instruction. Chicago: The University of Chicago Press, 1938, 128 pp.

[15] Etienne Wenger, Communities of Practice: Learning, Meaning, and Identity. Cambridge, MA: Cambridge University Press, 1998, 318 pp.

[16] Sue Willis, "Student outcome statements: What's it all about?," Cross Section, vol.6, no. 1, pp. 2-7, 1994.

[17] Sue Willis and Barry Kissane, "Systematic approaches to articulating and monitoring student outcomes: Are they consistent with outcome-based education?," Studies in Educational Evaluation, vol. 23, no. 1, pp. 5-30, 1997. 